\title{
Undisciplined disciples: everything you always wanted to know about ethnomethodology but were afraid to ask Yoda
}

\author{
Alan F. Blackwell ${ }^{1} \cdot$ Mark Blythe $^{2} \cdot$ Jofish Kaye $^{3}$
}

Received: 9 February 2015/Accepted: 20 December 2016/Published online: 13 March 2017

(C) The Author(s) 2017. This article is published with open access at Springerlink.com

\begin{abstract}
As computing technologies become ubiquitous in social life, social science increasingly becomes the study of those technosystems. Similarly, as technology corporations compete to design new ubicomp products, social science research is recruited as a design method. This paper presents an interpretive bricolage, exploring the relationship between social science and corporate technology research. It draws on a specific case study: the history of ethnomethodology during the lifetime of the Xerox EuroPARC laboratory. This interpretation relates to the ways that social and organisational authority is maintained through scientific knowledge, and the ways in which interdisciplinary design research engages with product users, customers and markets.
\end{abstract}

This work was performed while Jofish Kaye was an employee of Microsoft, Cornell University, Nokia Research Center and Yahoo Labs.

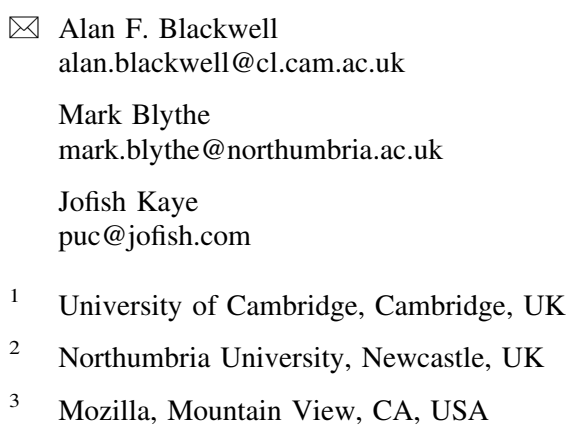

\section{Introduction}

HCI as a discipline depends on the rigorous study of human users and/or their social context. ${ }^{1} \mathrm{HCI}$ is also a design discipline, responsible for the creation of new technological products-the vision of ubicomp is above all else a technological vision. These two disciplinary commitments of HCI result in constant tension, because the methods of the human and social sciences are ultimately oriented towards the creation of theories rather than artefacts, while the corporate contexts in which technological products are imagined and created are oriented towards ensuring the delivery of novel products. In the case of ubicomp, the very ubiquity of the technology makes it even more difficult to disentangle the human and the technical—-the ubicomp vision presents us with an imagined future in which human society is a technosystem.

This article is a personal reflection on the history of $\mathrm{HCI}$ within the ubicomp frame, written by two professors of interdisciplinary design, and a corporate researcher. All of us have worked as ethnographers, as critics of technology, as teachers of design and as students of the imagination. The distinctive views and presentation devices that follow are an experiment that arises from our own creative engagement with the history of our discipline. This is not a science and technology studies-style critical history, nor is it an internal history of the field [3]; it is reflective design research, engaging with a rich set of background material,

\footnotetext{
${ }_{1}$ We use the umbrella term HCI, for the present audience, to include not only academic and professional venues using this name, but also CHI, CSCW, ubicomp, human factors, user experience, usability, experience design and others. The distinctions will be clear to those in the respective communities, but we do not wish to dwell on them.
} 
including over twenty interviews with key influencers in the fields of ubicomp and HCI at PARC and EuroPARC.

We explore the tensions inherent in our own practices through an in-depth analysis of a single case study - the encounter between the social science discipline of ethnomethodology, and the corporate context of Xerox Corporation at the time the ubicomp vision was being articulated. The CHI 2009 conference later featured a paper and panel discussion that harked back to this encounter between social science and design, with the provocative title "Ethnography considered Harmful" [12]. That combative claim was an appeal for the increasingly widespread practice of design ethnography to be replaced by "ethnomethodologically informed ethnography". Rather than a rebuttal or defence (our own project started several years earlier), our analysis offers an interpretation of the tensions that periodically lead to papers like that one. We believe that these tensions continue in HCI and in ubicomp today, although always expressed through newly emerging theoretical concerns, rather than the legacy of ethnomethodology alone.
The methods that we apply, in analysing these crosscultural encounters, explore the potential of bricolage as an alternative kind of rigour in social science [14, 25]. Yee and Bremner [46] suggest that design research, in particular, must adopt a perspective of bricolage. Although our project initially developed through semistructured interviews, archival research, historical analysis and application of the methods of grounded theory including open coding, preparation of memos, axial coding, diagramming, constant comparison, we do not wish to claim them as a source of authority. The experimental bricolage that we present here is instead a critical design interpretation of our subject, firstly reflecting on the ways in which a corporate laboratory is itself a designed artefact that reflects social structures of both science and the corporation, and secondly reflecting through design, in a series of interludes-fictional pastiches that we have constructed to develop our understanding of the dynamics we found.

First interlude—ethnography considered menacing
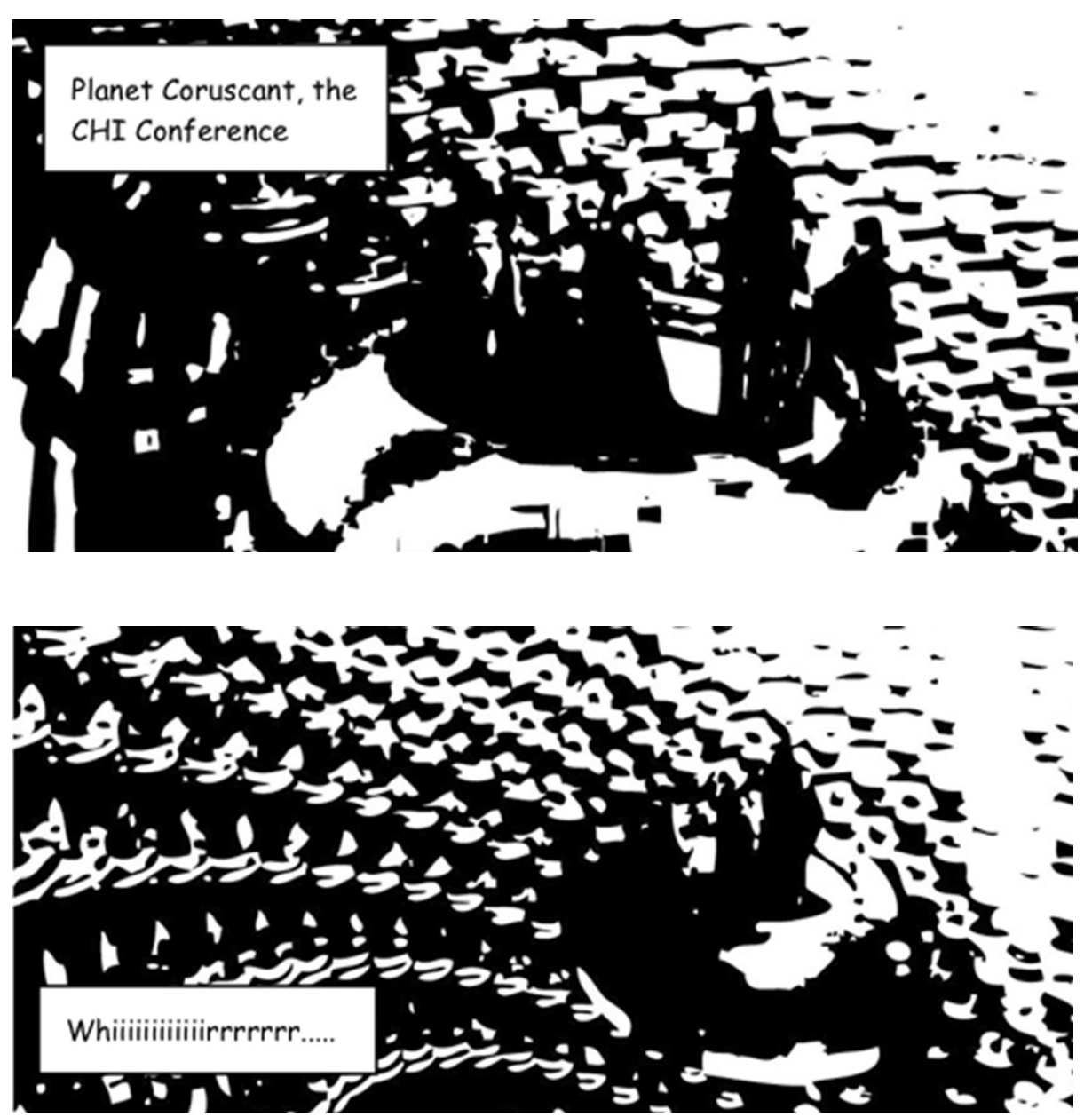

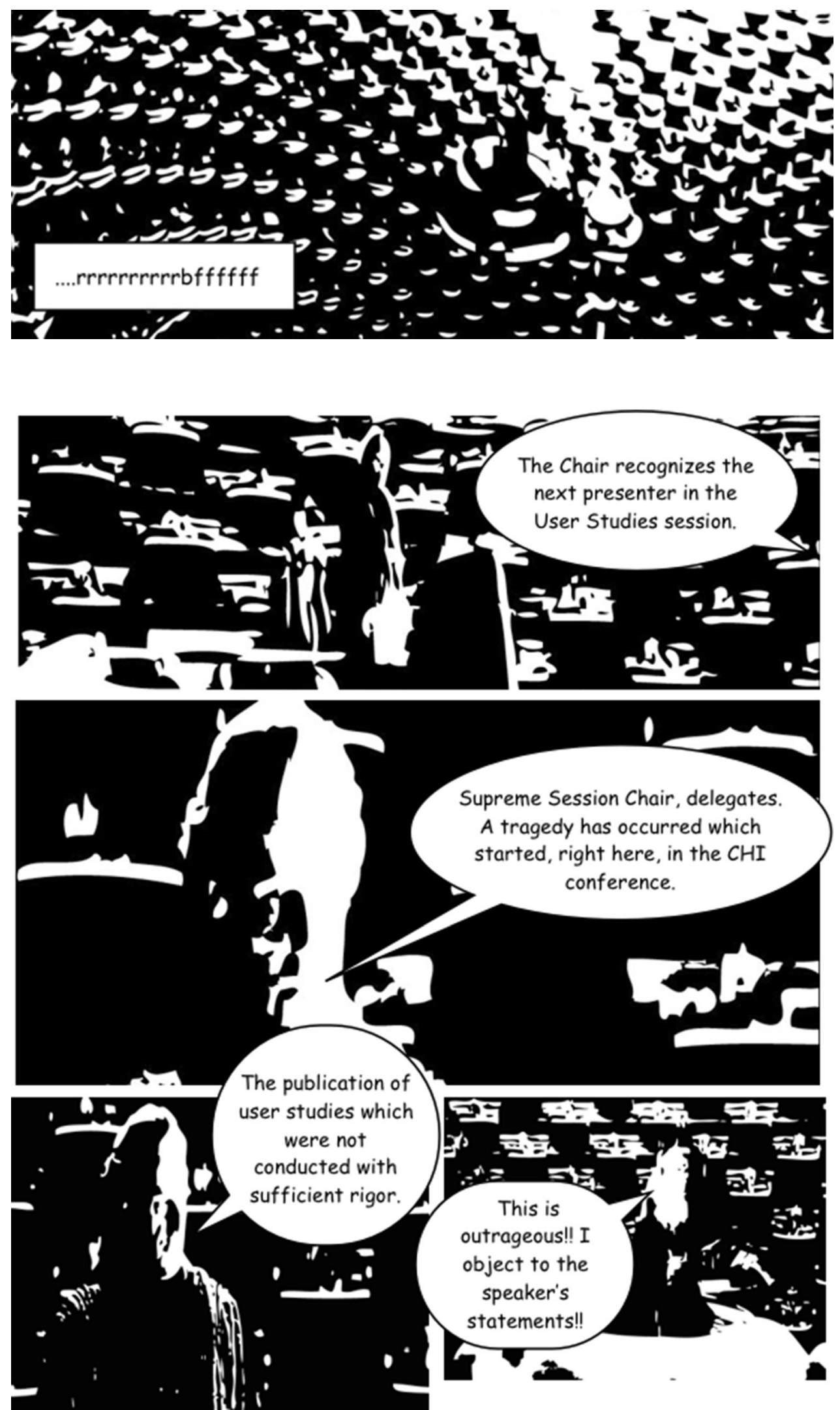


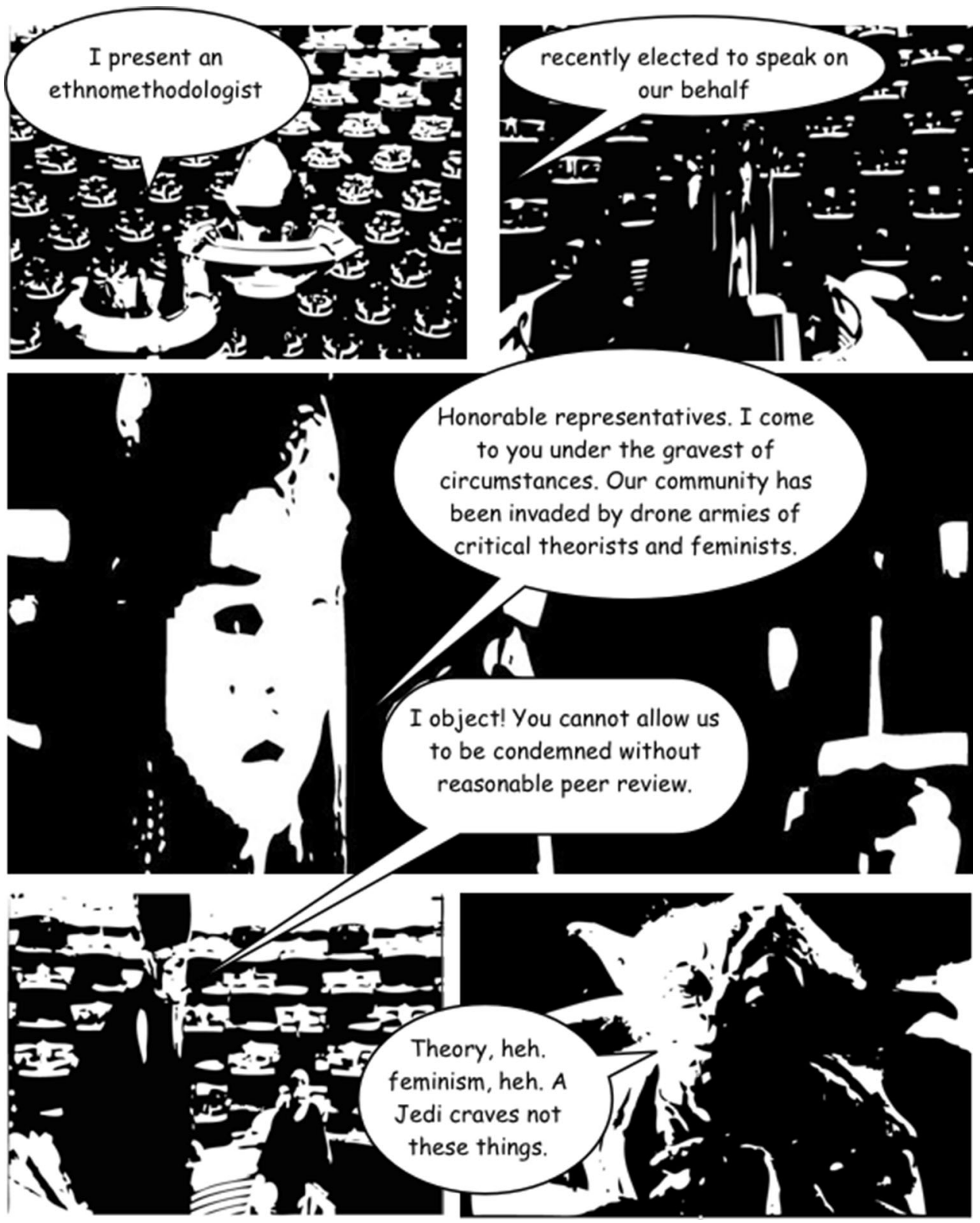

\section{Overview}

The setting for our study is Rank Xerox Cambridge EuroPARC, an extension of the activities of Xerox PARC ${ }^{2}$ that was based in Cambridge, England, for just over 10 years. As a relatively small laboratory, with a clearly defined lifetime from its founding to closure, EuroPARC offers an unusually well-constrained opportunity to explore large-scale trends in ubicomp research.

\footnotetext{
2 The Xerox Palo Alto Research Center, later sold by Xerox, and now operating under the name PARC. Although the official name of the laboratory was originally "Rank Xerox Cambridge EuroPARC" and subsequently changed, it is popularly known in HCI simply as EuroPARC, and we will follow this convention.
}

In the remainder of this article, we first present a brief history of EuroPARC - its foundation, broad areas of research activity and eventual closure. We then give a more detailed introduction to the specific research concerns of ethnomethodology and the way in which these were adopted into the work of PARC. The third part of the paper turns to a critical interpretation of the interaction between the technical and ethnomethodological research agendas, and the manner in which this interaction had a special character when conducted in a corporate context. Our interpretation draws an analogy with religious movements-and in particular, the differing ways that the English church engaged with society and the state. The final parts of the paper first review the subsequent influence 
of ethnomethodology within HCI and then consider the implications of these events for HCI more generally-both in the scientific context and in the applied context of corporate research.

The paper is also illustrated with three interludes, the first of which was Ethnography Considered Menacing. These are pastiches, borrowing from source material to create new texts. Our use of pastiche reflects the use of design fiction in HCI [6] as an appeal to fantasy, provocative and playful rather than claiming authority. We provide a brief note to accompany each.

Note on First Interlude: We chose to pastiche the Star Wars prequel The Phantom Menace to reflect on the controversial Considered Harmful session at CHI, because of an interesting link between the founder of Ethnomethodology, Harold Garfinkel and the character of Yoda. George Lucas has frequently cited Carlos Castaneda's The Teachings of Don Juan as an influence on Star Wars [24, 31], Castaneda was one of Garfinkel's PhD students and he claimed that his book describing Don Juan, a native American shaman, was based on in-depth field work carried out for his doctorate. It is now generally agreed that The Teachings of Don Juan is largely a work of fiction, and it has even been suggested that the charismatic and difficult figure of the shaman was based, in part, on Garfinkel himself [30]. When these facts were mentioned in a Facebook update by author Kaye, it inspired the following riff by Janet Vertesi:

'Yoda was definitely based on Garfinkel. Note the following parallels: 1. Playful deployment of the Breach $^{3}$, as in when he first meets Luke and rifles through all of Luke's stuff, playing with his flashlight, throwing tools everywhere. 2. Characterization of the work of ethnomethodology being concerned with practice and actors' accounts, not causal explanations that require an already-structured Society: Yoda/Garf: "No, no, there is no WHY!" 3. Characterization of the work of ethnomethodology being concerned with PRACTICE and what actors actually DO: Yoda/Garf: "No, try not. DO, or do not. There is

\footnotetext{
${ }^{3}$ Harold Garfinkel is perhaps best known for the "breaching experiments" which break unspoken rules of everyday behaviour. He famously asked his students to act like lodgers in their parents' home and insisted that they did not explain their subsequent bizarre behaviour. This strategy was used by other sociologists interested in everyday interaction, and many breaching experiments, like deliberately dropping litter or cheating at noughts and crosses, were carried out before there were University ethics committees to put a stop to them. Yoda's first meeting with Luke can with some accuracy be described as a breaching experiment of this kind because the ordinary rules of social engagement are suspended. Yoda does not reveal that he himself is the great Jedi Master that Luke seeks until he has first made Luke aware of his own preconceptions about what such a warrior should look like.
}

no try." 4. Characterization of being part of a small group of outliers railing against the rest of the field [Sociology/the Empire] and doing the TRUE work of the Jedi/Sociologist Yoda: "For my ally is the Force. And a powerful ally it is.... Beware the dark side... Once you start down the dark path, forever will it dominate your destiny.... Mind what you have learned, save you it can!" [..] 5. Some kind of resolution/absolution at the deathbed, when his student returns after having cut short his studies: Yoda/Garf: "No more training do you require. Already know you that which you need."Luke/Student: "Then I am a Jedi [/ethnomethodologist]." Yoda: "Oh-HO!! [laughs]. Not yet..." (Vertesi pers comm)

This Facebook exchange was clearly intended as comic rather than academic writing, but it captures some central concerns of ethnomethodology in caricatured form. The writings of Harold Garfinkel were described by our interviewees as obscure and difficult, which inspired us to follow cultural critic Slavoj Zizek who explains obscure Lacanian theory through popular film references.

\section{Historical context}

In 1986, Xerox PARC, at the centre of a booming Silicon Valley, was arguably the most prominent corporate technology laboratory in the world. Many countries outside the USA wanted a piece of the Silicon Valley action, and there was a growing trend of tax incentives encouraging major corporations to locate R\&D laboratories in local markets. The European Union was a huge market for Xerox, and a decision was made to create a laboratory in Europe, preferably somewhere business could be conducted in English, as soon as possible.

There was an obvious choice of location for the Xerox European laboratory. A 1985 economic consultancy report [37] had recently identified "The Cambridge Phenomenon"-an ancient university, after nearly 800 years, seemed about to become the centre of a high-technology economic boom. That forecast has turned out to be an accurate one, with the Cambridge area now the closest thing that Europe has to a Silicon Valley economy [26]. In 1987, Xerox was well ahead of the trend when it created the "EuroPARC" laboratory.

EuroPARC was founded for political and financial reasons, rather than to pursue a strategic research vision. Nevertheless, EuroPARC did have a research agenda; several factors in the late 1980 s conspired to determine that EuroPARC should focus on HCI, and the origins of ubiquitous computing. It had become clear that the Xerox PARC Alto and Star projects had helped define the 
personal computer, even though the business opportunity had been captured by IBM, Apple and Microsoft [39]. John Seely Brown, soon to become Director of PARC, was an artificial intelligence researcher with a strong interest in the study of computer users. And Allen Newell's applied information-processing programme, laid out in PARC AIP Memo 1 [33], had established a new scientific foundation for the field in the book "Human Computer Interaction" [10].

There were ample resources for HCI collaboration in Cambridge. The Medical Research Council Applied Psychology Unit (MRC-APU-[2]) was a major world centre of cognitive science and HCI research, and Neil Wiseman's Rainbow Group at the Cambridge University Computer Laboratory had been building innovative design workstations since the 1970s. Local research institutes such as Logica Cambridge had been industry leaders in the UK Alvey programme for applied AI. A senior technical manager from PARC, William Newman, had prepared a consulting report noting the benefits of locating the laboratory in his home country, near the Xerox technical centre 30 miles south of Cambridge. As a first generation developer of user interface tools, and co-author of the groundbreaking Principles of Interactive Computer Graphics in 1973 [34], Newman was an influential supporter of the HCI agenda.

EuroPARC was thus well-placed to become a pre-eminent international research centre in HCI. Tom Moran, one of the authors of the HCI book, was despatched from PARC to find suitable premises. He was welcomed to Cambridge by Richard Young, another past graduate student from Allen Newell's CMU group, who was now on the scientific staff of the MRC-APU. These various groups, in collaboration with colleagues and visitors from PARC, established a distinctive research agenda-the EuroPARC staff experimented on themselves, by building a ubiquitously collaborative "media space" environment, using technology to reflect on the social processes by which it was designed and the manner in which it was used (Buxton and Moran [9]). This early ubicomp agenda integrated the communication technologies pioneered at PARC with cognitive science-based models of users and designers, especially in the European project AMODEUS-Assimilating Models of Design, Users and Systems.

The early years of EuroPARC were dominated by these two projects-AMODEUS and RAVE (the Ravenscroft House Audio Visual Environment). The role of ubiquitous integrated media technology in collaborative work remained a central research theme throughout the existence of EuroPARC, extending to video-augmented work surface such as the Digital Desk [46], and use of technology such as the Active Badge from nearby Olivetti Research [43] to create ubicomp systems that were aware of the location and activities of users. These systems were instrumental in building the vision of the ubicomp future proposed by Weiser in The Computer for the 21st Century [44].

However, the intellectual agenda framed by artificial intelligence technology (from the user models of AMODEUS and the Card, Moran and Newell book, to the Lisp machines that controlled RAVE) was receiving a significant challenge from a young researcher at PARC. The work carried out by Lucy Suchman presented a fundamental critique of the approaches to human-machine interaction derived from cognitive science, based largely on her study in the early 1980s of an attempt at PARC to create a new user interface for a Xerox copier. This work was receiving increased attention at the time EuroPARC was being founded, after her $\mathrm{PhD}$ dissertation was published as a book [40].

Suchman had studied video tapes of people trying to use the new machine, revealing that they did not approach the machine with a detailed plan of what they would do, but rather came with a general goal and responded "on the fly" to events as they occurred. This was contrary to the general models of planning and problem solving that had become established in the cognitive science literature, and that had until then formed a central theoretical assumption in HCI. Her book offered not only a fundamental critique of the theories underlying $\mathrm{HCI}$, but also a new way of proceeding with user research that seemed to be better grounded in the reality of social behaviour.

We return to her social science commitments in the next section. The immediate impact for EuroPARC arose from the fact that John Seely Brown was an advocate of Suchman's work and sent her to the UK to recruit like-minded researchers for the new laboratory. Although she only made occasional visits to Cambridge, her collaborator on the photocopier project, Austin Henderson, was appointed as a travelling envoy between EuroPARC and managers at PARC. While the original research agenda for the laboratory had been technical and cognitive, the middle years of EuroPARC were characterised by a profound intellectual shift. This was driven in part by Brown's passion for "radical" interdisciplinary research, but also in part by the realisation that $\mathrm{HCI}$ as a whole would need to change in response to the dynamics that Suchman and Henderson had observed.

This broad intellectual agenda at EuroPARC flowered through the first half of the 1990s, but became more constrained when staff were told that all research must be related to the core Xerox business as "The Document Company". This can be read as a reasonable corporate response to the growing executive embarrassment from popular business books and case studies documenting how Xerox "fumbled the future" of the personal computer industry [39], rather than a reaction to the EuroPARC agenda itself. In the late 1990s, EuroPARC was closed, with remaining staff transferred to a Xerox software 
engineering research centre in Grenoble. The Grenoble site continued research into Document Content Models, Document Structure, Knowledge Management, Linguistic Platforms and Middleware. According to the historical archive on the Grenoble website, there had been a small amount of technical research at EuroPARC ("from Digital Desk to CamWorks"), with little reference to the ubicomp projects of RAVE, Active Badge or AMODEUS. But the most substantial legacy of EuroPARC according to that archive is the study of "Work Practices" using the methods of ethnomethodology.

We wish to emphasise that this section has been intended only as a brief introduction for those unfamiliar with the context, not an authoritative history of EuroPARC. In developing our own interpretation, we note that in a small laboratory such as this, many of the most significant dynamics may be interpersonal and contingent, rather than intended outcomes of organisational design, as has been observed by EuroPARC researchers themselves (e.g. [22]).

\section{Ethnomethodology}

This section is an introduction to the concerns of ethnomethodology and especially its introduction to HCI via the work of Lucy Suchman. The field of ethnomethodology is associated with the work of two California sociologists, Harold Garfinkel and Harvey Sacks. Although the particular concerns of the two are distinct, it can be difficult to disentangle them, especially in the ways they have been adapted to HCI. This difficulty results in part from Sacks' early death in a car crash, but also because much of their early influence spread through lectures and circulation of unpublished manuscripts. We follow common practice in referring to them as "sociologists", although they drew heavily on linguistics, Garfinkel had been at Harvard at a time when the distinction between anthropology and sociology was eliminated, and many of Garfinkel's students at Xerox were registered for degrees in anthropology rather than sociology.

Nevertheless, both were primarily concerned with the practicalities of everyday social activity, in contrast to larger-scale social theories. Sacks is best known for the development of Conversation Analysis, in which the mechanisms by which social interaction is accomplished are uncovered through transcription and close inspection and repetition of recordings. Garfinkel's term ethnomethodology also expresses a concern with the methods by which ordinary people construct social activity as a dayto-day achievement. "Methodology" is the term he proposes to describe the study of these ordinary methodscrucially, his term should not be read as an interest in professional research "methodology". Similarly, the prefix "ethno" is not a reference to established professional research methods of "ethnography", but a reference to a population of ordinary people (the ethnos) whose achievements are to be studied, much as ethnomusicology is the study of the music of a particular group of ordinary people.

Ethnomethodology is a relatively minor movement within social science as a whole. The comprehensive Sage Handbook of Qualitative Research devotes only a few of its 1200 pages to ethnomethodology, outlining Garfinkel's insistence that society is not shaped by "social forces" but locally produced "practices of mundane reason". These involve language, actions and objects that are "indexical"-dependent on context [14]. The Handbook places these observations in the context of Foucault's concern with language and practice, which were published around the same time. However, Foucault's analysis emphasised (rather than denied) the role of social systems and structures in the constitution of discursive practices. Garfinkel championed the individual by arguing that he or she should not be treated as a "cultural dope" acting in accordance with social theories. Although many of the ethnomethodological criticisms of sociological method may have been justified, Garfinkel was not the only person making them. The same critique was advanced by Glaser and Strauss in their development of Grounded Theory [21] which insisted that theory should emerge from data rather than pre-existing sociological categories. But ethnomethodologists were unusually vehement in their condemnation of pervious sociological endeavours, characterising the entire discipline as fundamentally misfounded. They were also, and perhaps consequently, unusually marginalised:

the ethnomethodologists used their critique of the methodology and epistemology of much conventional sociology [citing Cicourel 1964] as form of counter attack against critics who attacked them for the sociological irrelevance and substantive triviality of their own findings ([32]: p 183).

This assessment of the impact of ethnomethodology concluded:

Ethnomethodology shows individuals merely to be making sense of things as best they can, producing utterance and explanations which are acceptable within their communities, on the whole covering over the many moments of uncertainty, ignorance and indecision they experience in their encounters with the world. It has offered a somewhat quietist view of social life, except in the intransigence it has sometimes shown, as a movement, towards other elements of the discipline of sociology. [32]: p 192

Despite the fact that the apparent importance of ethnomethodology in HCI formed the initial motivation for our project, we found that the senior anthropologists we 
interviewed expressed surprise that a Californian movement they recalled for a brief vogue in the 1960s would have widespread influence today. In his comprehensive overview of applied research methodology, Colin Robson offers the summary that:

Ethnomethodology is not known for its accessibility, and conversation analysis has been similarly criticized, a frequent complaint being that its practitioners tend not to make their methodology and procedures comprehensible to researchers from other disciplines [36].

As we have noted, it is essential to remember that ethnomethodology is the study of the methods used by ordinary people, not an ethnographic research methodology. This key distinction is not widely understood in HCI and seems to have been a mystery even to some of those working at EuroPARC. However, it turns out to be an essential element of this story. Garfinkel delighted in a role as an iconoclast, and it seems certain that his deliberate creation of the word ethnomethodology, a title likely to confuse all other social scientists, was mischievously motivated. Nevertheless, his irreverent and disruptive attitude to both social institutions and the established concerns of sociology was also a potential source of insight. For example, Suchman applied Garfinkel's approach to understanding the complexities of human-human interaction to human-machine interaction in her study of photocopier use at Xerox. In her words:

The machine was a relatively large, feature-rich photocopier that had just been 'launched'... The machine was advertised with a figure dressed in the white lab coat of the scientist/engineer, but reassuring the viewer that all that was required to activate the machine's extensive functionality was to "press the green [start] button". It seemed that customers were refuting this message, however, complaining instead that the machine was... "too complicated"... I [convinced] my colleagues that we should install one of the machines at PARC and invite our coworkers to use it. My analysis of the troubles evident in these videotaped encounters ... led me to the conclusion that its obscurity was not a function of any lack of general technological sophistication on the part of its users, but rather a lack of familiarity with this particular machine... the machine's complexity was less tied to its esoteric technical characteristics than to mundane difficulties of interpretation characteristic of any unfamiliar artifact...

The main observation of [conversation analysis] was that human conversation does not follow the kind of message-passing or exchange model that formal, mathematical theories of communication posit. Rather, humans dynamically co-construct the mutual intelligibility of a conversation through an extraordinarily rich array of embodied interactional competencies, strongly situated in the circumstances at hand (the bounds and relevance of which are, in turn, being constituted through that same interaction). I accordingly adopted the strategy of taking the premise of interaction seriously, and applying a similar kind of analysis to peoples' encounters with the machine to those being done in conversation analysis. [41] pp 10-13

As with our historical overview, it is necessary to emphasise that this section should not be regarded as a comprehensive introduction to the field of ethnomethodology - that would require a far longer paper! In particular, although we have drawn primarily on work by Suchman for its clarity and relevance to our topic, we do not wish to suggest that hers was the only channel by which ethnomethodology influenced HCI or EuroPARC. Gitte Jordan was extremely influential at PARC, as was contact between EuroPARC and the Manchester group of British ethnomethodologists. As noted in the concluding caution to our historical overview in the previous section, many aspects of these encounters between social science and technology research were contingent outcomes of personal dynamics within a small laboratory, rather than intentional organisation design. The combative presentation that was characteristic of ethnomethodology, arriving in the context of a scientifically oriented technology corporation, thus resulted in a distinctive style of applied social science.

Garfinkel's work was a radical critique on Sociology as it was practised in the late 1950s and early 1960s. He argued that sociologists by and large reproduced existing sociological accounts of whatever phenomenon they were supposedly studying. Mainstream academic sociologists ignored the interpretations of the people they claimed to study, disregarding "members' accounts" and treating them as "cultural dopes" taken in by ideological structures of which they were largely unaware. Ethnomethodologists have long characterised themselves as an embattled minority opposed to the dominant schools of Sociology. Many of our interviewees noted that it was difficult for ethnomethodologists to get jobs in Sociology departments as they had written papers fundamentally hostile to the entire academic enterprise of Sociology. Although ethnomethodology sought to fundamentally change sociology, it is now an historical footnote in that discipline. How then did it come to be such a significant force in the study of human-computer interaction?

Second interlude-the teachings of Don Juanfinkel:

Many students of social science in 1970s California considered themselves to be ethically motivated. 
Anthropology provided an opportunity to explore and advocate the rights and traditions of indigenous people, including those among nearby Native American and Mexican populations. These also promised access to alternative spiritual traditions that were welcome within the broader context of the Californian new age. For example, Lucy Suchman told us that she had originally commenced her own anthropology studies in part because of her interest in traditional wisdom, and in part for the opportunity to engage with oppressed minorities.

Among many exotic elements of Californian research culture during this decade, one of the most intriguing was the case of Carlos Castaneda, a student of Harold Garfinkel at UCLA, who later presented the results of his "field work" in a popular book, The Teachings of Don Juan: A Yaqui Way of Knowledge [7]. Although couched in the language of social science, the real attraction of the book was his depiction of Don Juan, a Yaqui Indian shaman, who provided him with spiritual insight and magic powers through the use of drugs prepared from the peyote cactus, datura plant and special mushrooms. His narrative of spiritual enlightenment and self-discovery was followed by an analytic appendix (perhaps seldom read by fans), presenting the theoretical modes in which the research had been undertaken. As previously noted, it has been argued that Castaneda did not actually perform the fieldwork with Don Juan that he claimed, but instead based the character of Don Juan on Garfinkel himself [30]. The following pastiche presents a composite experience of a researcher at Xerox EuroPARC encountering the teachings of Garfinkel, in the style of Castaneda, but with a close resemblance to the experiences reported by Mandell. This pastiche takes the form of a mashup, splicing text from Garfinkel's Studies in Ethnomethodology [17] into the narrative, as Garfinkel's prose style is difficult to exaggerate.

\section{The Teachings of Don Juanfinkel}

It was summer of 1983 and I was a $\mathrm{PhD}$ student in Computer Science at the University of California when the teachings began. I was talking with a friend who was one of the interns in our lab when suddenly he leaned towards me and whispered excitedly that the old man, sitting on a bench outside eating a sandwich, was a great expert on everyday interactions. I asked him to introduce me to this man. My friend went out and greeted him. After they had talked a while he signalled me to join them but immediately left me alone with him not bothering to introduce us. He was not in the least embarrassed. I told him my name and he said his name was Donald Juanfinkel. There was a long silence but it was not strained. I told him I was interested in everyday interactions, although in truth I knew almost nothing about this subject I pretended I knew a great deal and began to talk. As I rattled on, he nodded slowly and looked at me but said nothing. I avoided his eyes and we finished by standing, the two of us in dead silence. He finished his sandwich, closed the box and said goodbye.

I made a point of finding out where Donald Juanfinkel's office was and later visited him several times. On each visit I tried to lead him into talking about everyday interactions but each time without success. We became, nonetheless friends and my investigations were forgotten. At first I saw him as a rather peculiar man but those around him believed he had made great discoveries. I had known him a whole year before he took me into his confidence. He possessed a certain knowledge that he had discovered through many years of long isolated study, this knowledge he named ethnomethodology. He had chosen me to serve as his apprentice but warned that I would have to make a very deep commitment and that the training would be long and arduous.

I began my apprenticeship to Don Juanfinkel later that year. My visits lasted longer in the summer but my research in computer science meant I could not make the full commitment I needed to become an ethnomethodologist and the training was ultimately a failure. But I will never forget the day it began.

After many months, Don Juanfinkel said that he had something to show me. We walked down long corridors, past biology labs and air conditioned machine rooms, to his office. Behind a heavy door was a musky room lined with books. On the desk was a video editing machine - the most sophisticated I had ever seen. I reached out to touch it, but he motioned me away. He said 
he had been analysing a video of a conversation that took place around a word processing machine. He believed that he now thoroughly understood "an observable and reportable situated practice of looking and telling". I waited for him to explain what he meant by "observable and reportable situated practice of looking and telling" but he made no attempt to elucidate the point. He played a short video clip showing the beginning of a conversation between a man and a woman. The woman was sitting at a word processing machine and said "Hi Sam" to a man who replied "Hey Diane". Juanfinkel stopped the tape after this exchange. Playing only these few seconds he rewound the tape and played it again and again. I asked if we could watch the rest of the clip. No! This would be too much for me. Even he could not perform a spontaneous ethnomethodological analysis of a whole conversation. $\mathrm{He}$ looked at me expectantly waiting for my interpretation. I suggested that it was interesting the way one speaker knew when the other had finished and that it was their turn to talk. His face was impassive and he shook his head. He had posed a riddle and I was to solve it myself without further deliberation. Several times I asked for a clue or at least a hint as to how to proceed in the analysis.

He suggested that I walk around the office while I watched the tape again. I began to pace around the room. "Everyday affairs are identical with members' procedures for making those settings "account-able" he said. If I kept this in mind then the analysis would be clear. I argued that I had no idea what he really meant because I couldn't conceive the problem. He became very annoyed with me and accused me of not listening, saying that perhaps I did not want to learn. I sat on the floor amongst his books in dejection. After a while he explained to me that when he spoke of procedures for making settings accountable, what he really meant was "endless ongoing, contingent accomplishments carried on under the auspices of and made to happen as events in the same ordinary affairs that in organising they describe". Still I failed to grasp his meaning.

I argued that the fragment was too short. How could I know what was going on from such a brief exchange? My arguments were futile. He got up and warned me very sternly that it might take me days to figure it out. He told me to remember that " the practices are done by parties to those settings whose skill with, knowledge of, and entitlement to the detailed work of that accomplishment - whose competence - they obstinately depend upon, recognise, use and take for granted." His face was stern and his eyes flashed enigmatically "the fact that they take their competence for granted" he continued "itself furnishes parties with a setting's distinguishing and particular features, and of course it furnishes them as well as resources troubles, projects and the rest"

He went out of the office and down the long corridor to the toilet. He returned directly, pointed at the machine and I tried again. Staring intently at the screen I concentrated on intonation, timing, inflexion, every subtle and nuanced cadence. Were they flirting? Juanfinkel scowled silently at the suggestion. Nothing came to me. The man was wearing a tie, she was dressed informally. Could he be her superior? Was the exchange in someway connected with power, organisational politics? Gender? Juanfinkel barely restrained his temper as he told me to look to the data not my theories. After a while I began to think there was something sarcastic, mocking in the woman's tone. They were once lovers! I declared. When he says "Hey Diane" he is really attempting a reconciliation, here "hey" means I love you! Juanfinkel strode over to me with a terrible look of fury on his face. He grabbed me by the shirt and told me I was a fool! Calming down and releasing me he said very slowly and insistently "it is every society's locally, endogenously produced, naturally organised, reflexively accountable, ongoing, practical achievement, being everywhere, always, only, exactly and entirely, members' work, with no time out, and with no possibility of evasion, hiding out, passing, postponement, or buy-outs, that is sociology's fundamental phenomenon!" I lay down on my back and put my hands under my head like a pillow and watched again. I rolled over and lay on my stomach for a while. I repeated this rolling process over the entire floor. Juanfinkel rolled a joint and we watched the tape again as we smoked it. The sun began to set and I watched the sky glow red through the small window. Suddenly I noticed the green light of the curser on the woman's word processor flickering. "Is it that? Are they both just word processors? Is that what you're telling me?" Juanfinkel rolled his eyes in despair and his 
shoulders slumped as if he were ready to give up. The tape played for what seemed like the thousandth time. "Hi Sam" the woman said "Hey Diane" came his reply. What did it mean? What did he want? Suddenly I had an idea which I thought was brilliant. I jumped to my feet and tried to remember Juanfinkel's exact words as he introduced the clip. "Is it," I cried " an observable and reportable situated practice of looking and telling?".

Juanfinkel blinked at me enigmatically, "Look to the data" he replied sternly, put on his coat and went out to dinner. I watched the tape obsessively. I sat in every spot on the floor. Viewed it from his chair. Closed my eyes. Stood on my head. Still there was nothing. When Juanfinkel returned six hours later I was lying on the floor almost delirious and moaning " but they're just saying hello, they're just saying hello".

I heard Juanfinkel talking and laughing above my head. I woke up.

"You have just had your first ethnomethodological insight" He said.

It was not clear to me that I had had any insight at all and in fact, I was not even convinced there was anything to have an insight about. I could not avoid feeling that the whole experience had been forced and arbitrary. Juanfinkel on the other hand was very sure I had succeeded and acting in accordance with my success he was going to teach me about ethnomethodology.

\section{An interpretation of social science in design}

This section introduces the central interpretive agenda of our project. The overall structure is not a straightforward argument leading to objective conclusions, but a relatively subtle one-we offer a series of "variations on a theme", structured around a central analogy. The central analogy itself emerged from our interviews and documentary sources, but should not be regarded as a factual claim about either EuroPARC or ethnomethodology-it is an interpretive lens through which to explore the intellectual dynamics of HCI as a field.

\subsection{Doctrinal knowledge and social authority}

This is our theme: When corporate technology research crosses disciplinary boundaries, especially in the process of technology becoming "ubiquitous", how should a company determine which sources of authority are valid? All academic disciplines, or none? And which of the disciplines that constitute HCI carry the most weight in speaking to authority? Although a critical problem for HCI, these questions also mirror concerns in wider society. Helga Nowotny, the president of the European Research Council (and professor of Social Studies of Science), has written

With its historical rise, modern natural science took on some of the social functions that were formerly the provenance of religion. The distinction that science makes between the person who knows and the person who is ignorant is analogous to religion's distinction between the holy and the profane..... [This knowledge] is the basis for epistemic and social authority with which the scientific community speaks in the name of a higher order of knowledge that is beyond human control. From this firmly anchored conviction grows natural science's characteristic and sometimes vehement resistance to all attempts to uncover the social roots of its order of knowledge. [35] p 18

In the case of a corporate technology laboratory, the "social roots" of scientific knowledge include not only the researchers themselves, but also their engagement with customers-who may derive greater or lesser benefit from the products or may even be exploited when their own ideas are appropriated and sold back to them [42]. For ubiquitous computer technologies, the field of HCI becomes the nexus at which corporate knowledge must navigate between epistemic authority and social contingency, or the "holy and profane", in Nowotny's analogy.

We found it productive to use this analogy to explore the ways in which ethnomethodology introduced social concerns into a context where "higher orders" of technical knowledge had previously prevailed. Incidentally, many of those we interviewed made religious comparisons when referring to encounters with ethnomethodologists at EuroPARC, with those who were sceptical about ethnomethodology's value occasionally referring to it as a cult. This comparison predates the period of our study, for example in Gellner's opinion that ethnomethodology was caught between "Catholic" and "Protestant" tendencies in Sociology [19].

Rather than Catholic and Protestant (or holy and profane), we suggest that a more apt analogy for unpicking the role of scientific knowledge in the English context of EuroPARC would be the two forms of Anglicanism known 
as "High Church" and "Low Church". ${ }^{4}$ As the constitutionally established state religion of the UK, Church of England doctrine has always been implicated in political rule [8]. In the early nineteenth century, the phrase High Church became associated with the conservative Tory party, having doctrines that stressed apostolic order and the authority of the visible church, valuing obedience to ordinances and liturgical forms. Subsequent reactions labelled as Low Church included concerns with social activism and evangelism, emphasising personal faith and freedom of worship.

We must be clear about the analogical nature of our interpretation-we are not suggesting that any of those involved in EuroPARC were literally religious (they may or may not have been), or that there was actual "faith", "worship" or so on. Instead, we are concerned with social dynamics of the practices that arise around organised bodies of knowledge, which we argue share parallels whether those practices and knowledge are established in relation to spiritual questions or scientific ones.

In our interpretation of corporate research governance around ubicomp, we use the phrase High Church to emphasise the "higher orders" of knowledge that are "beyond human control" in Nowotny's phrasing-physics, chemistry, computer science-and Low Church to refer to the social roots of corporate action, among markets, users and customers. Many corporate research laboratories have experienced tension or transition between these axes, for example researchers at General Electric gradually departing the forefront of theoretical physics for a concern with markets [1]. To some extent, the dichotomy and its connotations of epistemic authority correspond to the commonplace distinction between "hard" and "soft" science, although we argue that there are more substantial implications of doctrine and power than generally acknowledged in those phrases, and also that social sciences can, on occasion, play a High Church role that might otherwise be associated only with hard science.

Unlike academic disciplines, corporations need not have any consistent theory base. But in a corporate research laboratory, theory must be accommodated within that organisational structure. Furthermore, stability is of mutual interest both to corporations and to academic disciplines. In British politics, there is a tendency for the highly structured High Church to be more closely associated with financial power and patronage. In a research context, we wonder whether structured and defensible theory might be more associated with the directors and administrators of

\footnotetext{
4 This analogy was originally prompted by an interviewee stating that sociologist of science Steve Woolgar called EuroPARC director Graham Button a "high-church ethnomethodologist". We are grateful for this observation, confirmed by Woolgar in conversation with $\mathrm{AB}$ (25 March 2011).
}

laboratories maintaining their organisations? This might be contrasted with a Low Church tendency to spend more time with customers, valuing personal experience, designing actual products, broadening markets and disrupting businesses.

\subsection{The High Church of cybernetics}

This section is the first of our "variations on a theme" each exploring a different way in which the High Church/Low Church analogy casts light on the intellectual agenda of HCI.

At the time PARC was founded, companies such as IBM, Bell and Xerox were creating bureaucratic infrastructure where large-scale information systems comprised a mix of human and automated information-processing units. Cognitive science offered a theoretical account through which human "components" could be interchanged with digital "expert systems" resulting from artificial intelligence (AI) research. ${ }^{5}$ The Xerox brand was one of those most closely associated with bureaucratic systems, and PARC had invested in AI research from its foundation. The birth of HCI in this laboratory was phrased as a proposal in AI (Newell's AIP Memo No 1 in 1974), although in High Church form, as a generic advance of scientific knowledge, rather than in relation to the Xerox photocopying business.

The first large scientific project at EuroPARC followed this agenda, under the European AI initiative ESPRIT. The AMODEUS (Assimilating Models Of Design, User and System) project continued Newell's direction, in collaboration with cognitive scientists at the Cambridge Applied Psychology Unit. However, the theoretical foundations of the project, and its apparent mechanisation of both design process and user, were early targets for the ethnomethodologists arriving at EuroPARC, following the critiques in Suchman's work. These often vigorous doctrinal disputes eventually led to a complete separation between EuroPARC and the Applied Psychology Unit, and indeed between EuroPARC and the whole of the Cambridge University establishment.

We suggest that this separation between theoretical and practical views of the customer was an inevitable outcome of the High Church dynamics in Newell's original PARC research agenda, concerned with scientific advance rather than immediate commercial opportunity. But there was no

\footnotetext{
5 The Stanford project leading to Dendral, generally credited as the first expert system, was initiated in 1963 with a research proposal to gain "insight into the relative roles of the human and machine components of these systems [...] invaluable in the further development of artificial intelligence, the programming of machines to simulate as far as possible those human cognative[sic] processes that we can begin to understand" (Lederberg [27]).
} 
people's revolution at PARC-the Low Church seldom retains long-term power. Instead, the managerial structuring of corporate research made it necessary to take the user-focused vigour of ethnomethodology and turn it into a new kind of High Church doctrine. Indeed, Debord had already identified sociology, alongside cybernetics and management science, as simply another of the "sciences of domination" that construct and reinforce systematised and alienated mass consumption ([13], Section 42).

\subsection{The Low Church of social critique}

This second "variation on a theme" takes a different tack to the first, this time exploring the intervention of social science within technology design research.

Low Church movements, in their social ministry and evangelism, focus their attention beyond areas of structured authority, in order to engage with a wider public. At PARC, the Work Practices group had initiated field research in the places where Xerox products were being used and maintained. John Seely Brown was a vigorous supporter of this programme of work and of the addition of anthropology (as they described the sociology/anthropology mix at UCLA) to the Xerox research agenda. He asked Tom Moran to create an even more "radical" mix of disciplines at EuroPARC. The key question, for a radical Low Church agenda, is whether the research focus on ordinary people that results from technology becoming ubiquitous is accompanied by a corresponding political consciousness.

Many social scientists at the time were aware of the focus on everyday life advanced by philosophers such as Debord [13] and Lefebvre [28], associated in Europe with attacks on the state and on corporate consumerism [16]. However, a postmodern philosophy with Marxist political commitments would have been a challenging investment for a global corporation, even if it did provide new insights to mass markets. Fortunately, the political commitments of ethnomethodology appeared to be minimal. Ethnomethodology offered vigorous critiques, but only of other academic disciplines (cognitive science, certainly, but most especially mainstream sociology). With its rejection of political theory along with all other social theory, ethnomethodology settled comfortably within the corporate laboratory. It also offered a distinctive style of intellectual certainty via its hostility to almost every other academic discipline. Universal dismissal could, in one sense, be an ideal starting point for interdisciplinarity_because ethnomethodology was equally opposed to them all.

Furthermore, the "methods" 6 of video protocol analysis taught by Suchman and Jordan were perceived by many we

\footnotetext{
${ }^{6}$ Note that we are reporting a misunderstanding, of those who were under the impression that ethnomethodology was a methodology.
}

interviewed from EuroPARC as ritualised practices, rather than being justified by explicitly articulated scientific principles. The refusal to theorise ordinary social accomplishments and practices (including the social practice of being a researcher) is of course core to ethnomethodology, as we have discussed. However, insistence on ritual is also characteristic of High Church liturgy (prescription of what should be done in church) rather than Low Church evangelical radicalism (individual believers free to interpret their insights and revelations through original expressions of faith).

Ethnomethodology was thus in the distinctive position at EuroPARC of fulfilling a Low Church strategic mission (engagement with users of ubiquitous technology) while presenting High Church styles of tactical conduct (doctrinal debate and guardianship of ritual). Whatever the personal motives of ethnomethodologists (and Lynch [29] protested that they did have strong ethical commitments, whether or not these were expressed through their work), this was not the primary concern of ethnomethodology. At EuroPARC, a fascinating choice arose between the Low Church path of radical design engagement with ubiquitous product users and the High Church of apparently hermetic rituals and doctrine.

\subsection{Cathedrals and culture}

This third "variation on a theme" explores the role of technology itself within the social enterprise of design research.

A key dynamic in the prominence of EuroPARC (and PARC) is the mass appeal of cool technology, just as for many on its margins the appeal of the High Church is aesthetic, rather than doctrinal. ${ }^{7}$ In the 1980 s, Xerox PARC was one of the great cathedrals of technological culture, alongside Negroponte's Media Lab at MIT, and Boulez's computer music research centre IRCAM. Just as the rich material culture of the High Church depends on power and privilege for ostentatious display, these early ubicomp laboratories had the coolest toys because they spent the most money. At EuroPARC, Bill Buxton, a digital arts researcher with close links to both IRCAM and the Media Lab, was invited to create RAVE-Ravenscroft [House] Audio Visual Environment-an extravagant network of video cameras, TV screens, broadcast-quality video cabling and computer-controlled video switches throughout the building. Together with the Active Badge system adopted from the nearby Olivetti laboratory, and projects such as the Digital Desk developed in collaboration with

\footnotetext{
7 The High Church offers ornate choral music, robes and vestments, stained glass and stone cathedrals, and incense-disparaged by Low Church adherents as "smells and bells".
} 
the Computer Laboratory Rainbow Group, these glittering prototypes were living demonstrations of the future-the science fiction-like imagination of ubicomp promoted by John Seely Brown and Mark Weiser [44]. ${ }^{8}$

A research agenda that understands the "user experience" of such imaginatively desirable technological and cultural products has become essential to HCI. However, critical reception of high culture, like the High Church, favours work in the avant-garde - properly theorised, and under the patronage of the established masters. Low culture and the Low Church, on the other hand, are popular and democratic, adopting elements of folk tradition. Finally, the High Church represents established tradition and mature taste, whereas the "happy-clappy" Low Church is portrayed as juvenile and trivial. Whether populist, clichéd or kitsch, the taste of the people is rarely celebrated as good taste.

The cultural appropriation of new ubiquitous technologies therefore poses a problem for corporate research managers-how can the politically contested sphere of culture be made an object of disinterested study? High Church privilege and hierarchy depends on a disciplined theoretical account of the knowledge it guards. Where the earlier programme of human factors, measuring user operation of products via perception and reaction times, was unproblematically a "natural science" (nineteenth-century psychophysics), the process of designing products within the aura of AI had become a more mutable "science of the artificial" [38]. But it was the desire for a "science of culture" as the rigorous study of human experience that led Husserl to formulate the methods of phenomenology. Husserl's phenomenology provided the intellectual grounding for the work of Garfinkel, for the European leftwing philosophers, and much of recent $\mathrm{HCI}$, especially via an influential UbiComp text by EuroPARC alumnus Paul Dourish [15].

The phenomenological response to the study of culture, in a setting less wealthy than the corporate ubicomp laboratory, could have been associated with more vigorous critique. Anthropologist Marvin Harris claimed that all phenomenologists, including ethnomethodologists, were actually (misguided) political radicals, whose true agenda was masked in "obscurantism" [23]. Certainly, the

\footnotetext{
${ }^{8}$ Ironically, both RAVE and the Active Badge UbiComp projects were motivated by the material shortcomings of the office premises that EuroPARC and Olivetti occupied. In Cambridge, the University owns all the grand buildings (including several near cathedrals), while companies in the city centre rented tall, thin buildings on narrow plots. Informal collaboration, or even casual contact, among staff on different floors of a narrow building was a challenge. Tom Moran (who had studied architecture before becoming a cognitive scientist) spent a great deal of time in these early years struggling with the idea of "re-designing" the building. He complained that Ravenscroft House was a "broken" building that could never recreate the collaborative atmosphere of the PARC premises.
}

impenetrability of many phenomenological texts, like the writings of Garfinkel himself, can make them hard to challenge. ${ }^{9}$ However, clarity of theoretical doctrine is not necessarily the most valuable contribution of the High Church to government, and we likewise found no sign of masked revolutionaries. Our High Church analogy suggests that the most important considerations may be the presence of ritual, an atmosphere of material extravagance, and readiness to debate doctrine across disciplinary boundaries-components all evident in the practices at EuroPARC.

\subsection{Commitment and crusades}

Our final variation on the theme of High Church/Low Church explores the personal dynamics of interaction between researchers in these intellectual contexts.

The great majority of those we interviewed, especially those who had been younger researchers at EuroPARC, revealed the extent to which their personal choices had been motivated by strong ethical commitments to understanding the needs and experiences of technology users. They often acted out of empathy for users and adopted roles as user advocates in the face of technical resistance. For example, we were told that Lucy Suchman's presentations at PARC became a "moral crusade" in which she wanted the computer scientists to agree not just the importance of what she was saying, but also the rightness. She attracted vigorous counter-attacks, in the same manner of the ethnomethodologists at EuroPARC who "laid into you" when advocating their own doctrines. Founding manager of PARC, George Pake, acknowledged this aspect of the PARC research culture in a classic of managerial understatement: "They would sometimes be rather intemperate in their criticisms of each other's ideas" [39].

An anonymised transcript of meetings at EuroPARC [20] reveals how users were represented in discussions over the design of the ubiquitous RAVE system. In these conversations between a cognitive scientist, a psychologist, a computer scientist, and a "physics graduate", ${ }^{10}$ some participants focus almost solely on technical aspects, while

\footnotetext{
${ }_{9}$ As Gellner put it, "the willfully obscure and undisciplined verbosity makes it impossible to be sure just precisely what it is that is being said" [19] p 446. Graham Button, the second of the Manchester-school ethnomethodologists to serve as Director of EuroPARC, told us that this was a desirable thing. Decoding such texts demands close reading and discipline, and Graham told us that he enjoyed nothing more than to settle down with a paper that would take him days to understand. Or in the words of one of Garfinkel's students, "It took many years (won't say how many) before I could read the first paragraph of [Studies in Ethnomethodology] with a fairly good sense of comprehension and competence" (Goode, unpublished manuscript).

${ }^{10}$ Individuals are not named in the transcript, although identities are apparent to those familiar with the setting.
} 
others introduce user concerns. We were intrigued to see that neither prior qualifications, nor subsequent reputation as HCI leaders, predict which of these was most concerned with users. The principal user advocate was in fact the physicist, a young female researcher who was one of several young women who "burned out", leaving both the macho atmosphere of EuroPARC debate and any future involvement in research.

EuroPARC did maintain close links with the participatory design research group at Aarhus in Denmark, and Liam Bannon in particular travelled regularly between the two during the earlier years. Nevertheless, it was the ethnomethodologists rather than the cognitive scientists or participatory designers, who eventually prevailed, becoming directors of EuroPARC, and the final remnant of user research by the time the laboratory closed.

Ultimately, our interpretation is that the Low Church of user-oriented design research cannot aspire to "the higher order of knowledge that is beyond human control" [35], because its interventions are motivated by situated human need, with research methods and analytic stances chosen on relatively pragmatic and contingent grounds. The central concerns of HCI might be seen as tarnishing ethnomethodology with Low Church associations-Gellner [19] worried that demand for easy to use and "intuitive" products was a symptom of the lazy consumerism that tempted young Californians into ethnomethodological "subjectivism" rather than accepting the discipline of proper scholarship. However, the experience at EuroPARC demonstrates that the hierarchical context of the corporation can provide precisely the High Church credentials for a social science that attains authority through doctrine, conduct, and display, despite the apparent democratic accessibility of ubiquitous computing products.

Third interlude-EuroSerfs Note. Microserfs is a novel by Douglas Coupland set in a Silicon Valley startup dominated by Microsoft under the charismatic personality of Bill Gates. The novel takes the form of diary entries, emails, and project notes made by the narrator Daniel Underwood. Coupland employs a number of experimental techniques throughout the novel such as presenting one section of it in binary code. Elsewhere, whole pages are filled with single words to create primarily visual effects. Font sizes are sometimes varied wildly at the start of chapters so that single words can take up a third of a page. Coupland based the novel on research at Microsoft and Apple. The text is particularly appropriate as source material for a pastiche as the historical moment is roughly the same as the period this paper considers and the central characters are approximately the same age and at the same stage of their careers as the EuroPARC researchers. The self-described "young turks" at EuroPARC held themselves at an ironic distance from "the dark side" of management, and the clever ironic humour related to us in interviews closely resembled that captured in Coupland's work. Here, we imagine the social contexts and social implications of ubiquitous computing infrastructure development. 


\section{EUROSERFS}

\section{What Gomputers do not know, you could fit into a human \\ body.}

Until machines have hodies like ours Artificial Intelligence is doomed, but
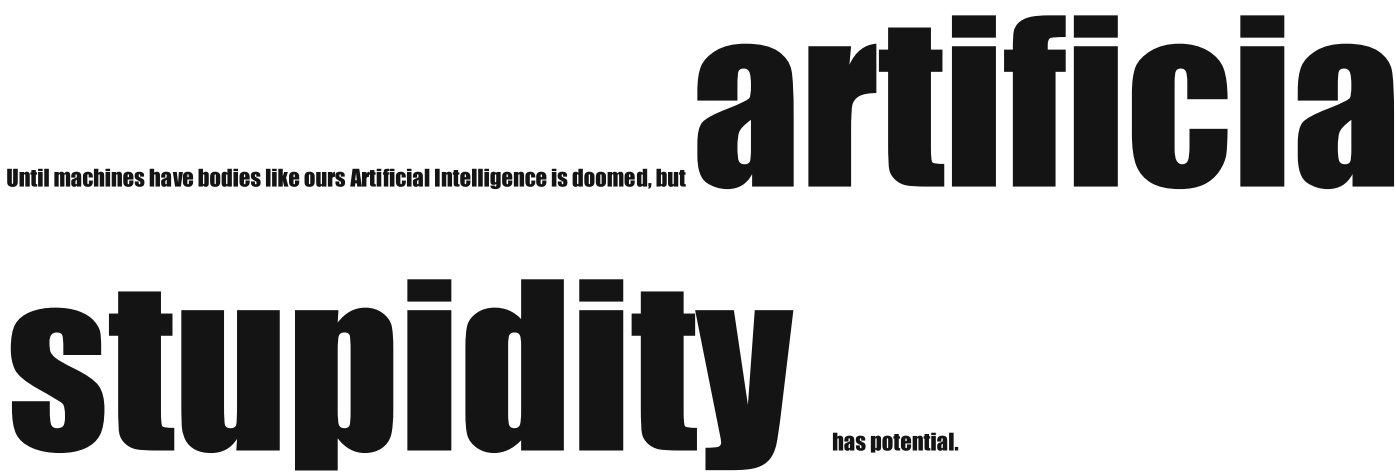

\section{If we were machines}

have the gift of being eternal and I want you to understand

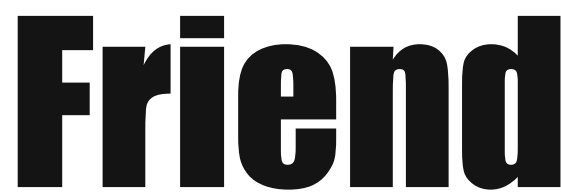

Or

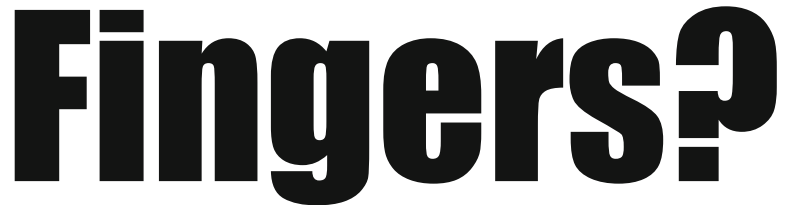




\section{Steps: My Trip}

to the

\section{Video Network Seminar}

By Daniel Underwood

1.

In the future text, audio and video links will allow me to talk at any time to all of the people l've been trying to avoid all these years.

\section{2.}

That's right, I'll be sitting at work coding and a message will pop up in the side of the screen saying that Mike wants to talk. He will literally never have to leave his office. How happy he will be eating flat food posted under the door and issuing his electronic edicts. 0 brave new world that has such avatars in it!

3.

The reason that we like conversations is that they are a break from work. We seem set on creating a world where work will be a break from conversation.

4.

When displays and cameras are everywhere we will give the illusion of popularity to people who would otherwise know themselves to he totally socially incompetent.

5.

If we're going to design systems for social interaction then we need to understand how normal people relate to each other in real life. This will be the higgest challenge Mike has ever faced. He does not do normal.

\section{6}

Luckily for us we have ethnomethnowhatnows in this Lab. If I understand them correctly the whole of sociology was in a complete mess until some guy named Garfield turned up in the seventies and fixed it. I can well believe this: sociology majors were always total losers at school. Having your entire discipline all fucked up for a hundred and fifty years would he enough to make anyone grow a beard and wear corduroy.

1

What the hell am I doing in Cambridge? It feels like I'm in a made for TV movie. The undergraduates in the supermarkets bray at each other like tomorrow belongs to them. No my Eton educated friends, tomorrow belongs to Mike.

8.

The models of video networking [as far as I can see]

1] The Little Brother Model

like Orwell but we're spying on each other to save on operational and administrative costs

2] The Pervert Model

Nohody likes heing watched, unless they like being watched

3] The Nothing Changes model

It's the water cooler, it's office gossip - remind me to tell you what we found Susan doing in the paper cuphoard. 
4] The Terminator Model

Skylab gains consciousness and the systems we design have such unpredictable effects that we'll be lucky to get out of our cubicles alive.

5] The "Game for a Laugh: Model

Watching us watching you, watching us watching you. Footnote: Game for a Laugh is a British version of Candid

Camera with additional self loathing and spite.

9.

I wonder if we over-sentimentalise how much we enjoy interacting with each other. If the normals we hear so much about are in any way like these ethnomethnowhatnow guys we should move away from modelling interaction to modelling one way yelling.

10

All of our projects must now relate to the Xerox business model. I have never been more painfully aware that I work for a photocopying company. I am just two steps up the food chain from - can I interest you in any toner today?

11

Karla and I met this cool looking woman at Iunch. She said she'd been talking to some fat guy with a beard ahout an idea she had for a project and he said it had "trousers". Karla wanted to know what the hell that meant, was it some kind of sexist derogatory put down? The cool looking woman said it meant - did the idea have legs? I suggested a better question might be - did the idea have hot pants, this being a gender neutral term.

12.

Ideally in a video link you would have a sense of presence in a meeting with the added bonus of having a volume control on whoever is talking.

13.

At Gambridge University everyone is working on a novel. At Cambridge Polytechnic everyone is working on a screenplay. Here we're working on snappy email sign offs.

14.

The avoidability problem. [Engineering the possibility of pretending to be busy]

15.

I think Jean Michelle Jarre and Top Gear have been the biggest influence on social networking so far.

16.

I wonder if l've missed the boat on online networks I think you only ever truly feel comfortable with the level of technology normal to you at he age of five. Sure, l'Il look at a screen but what happens when I need to stick my hand in a bucket of goo?

17.

In the end the internet won't resemble conversation so much as television.

18

Wait a minute, what the fuck is ethnomethnowhatnow? I thought I had it for a minute but it's gone. It may wear trousers, but it sure don't wear hot pants.

6 The afterlife of ethnomethodology in HCI

Over the past 30 years, there has been increasing demand for design research to include ethnographic methods, especially as socially connected technology becomes ubiquitous. There has been a substantial international community based around EPIC (the Ethnographic Praxis in Industry Conference) and the anthrodesign mailing list. Software development companies and design consultancies often include an "ethno" (used loosely to refer to an ethnographer with experience in fieldwork as opposed to a laboratory-based usability researcher) whose responsibility 
is to carry out field research among users. These practices gained prominence through early coverage of John Seely Brown's enthusiasm for anthropology at PARC, but they are now ubiquitous. It is unsurprising that many $\mathrm{HCI}$ practitioners might assume "ethnomethodology" refers to the professional "methodology" that the "ethno" researchers use-that is, ethnographic methodology.

The ethnomethodologists in HCI do not always discourage this assumption. Andy Crabtree's textbook "Designing Collaborative Systems" [11], described as "... a significant contribution to ethnomethodology" by Lancaster's John Hughes, and with an encomium from EuroPARC director Graham Button on the back cover, elides the difference throughout. The word "ethnomethodology" almost never appears in the text of the book (in fact, it is used more times on the cover than inside). However, a close reading of these uses is revealing. In summarising the value of the book after a final application case study, the author states that it has "served to elaborate methodological ways in which ethnography may be utilized in the evaluation process and be married to design practices..." (p 162). Two sentences later, the concluding chapter opens with an apparent reiteration that the purpose of the book has been to use "ethnomethodologically informed ethnography in the creative process of design". It takes a careful reader to realise that, between summarising the empirical evidence and drawing the primary conclusions, the meaning of a key word has changed-it is no longer a methodological way of using ethnography, but ethnomethodologically informed ethnography. The first phrase need not refer to Garfinkel at all, while the second certainly does. Although Garfinkel himself always denied that ethnomethodology is a research methodology, the authority of ethnomethodologists in $\mathrm{HCI}$ is bolstered by framing it as such.

Paul Dourish's reflection on this dynamic, in our interview with him, was that "HCI needed ethnography, and it got ethnomethodology". But it should be added that the extent of its influence can be over estimated. A search of the ACM digital library indicates that although references to ethnography originally drew on ethnomethodology, the proportion that do so has steadily decreased (Fig. 1).

These bibliographic data are clearly a crude indication of changes in theoretical affiliations, but they tend to confirm that although the introduction of ethnographic methods to HCI was initially associated with the work of ethnomethodologists, ethnography in general has subsequently become a more common practice than ethnomethodological studies or "ethnomethodologically informed" ethnography. The period of greatest influence for ethnomethodology in $\mathrm{HCI}$ occurred within the period that EuroPARC was operating - and even this was contingent on the particular dynamics of that laboratory. Since the closure of EuroPARC, mainstream ethnographic HCI has proceeded quite vigorously without being ethnomethodologically informed.

Although the relative proportion of ethnomethodological studies in HCI has fallen, some have persisted in distinguishing ethnography in general from ethnomethodologically informed ethnography in particular. The polemical CHI publication "Ethnography Considered Harmful" [12], like Garfinkel's own polemics in the 1970s, views marginalisation as resulting from a lack of discipline on the part of all other social science. Ethnomethodology sets a strict agenda separating it from mainstream social science, aiming for a rigorously descriptive programme rather than a

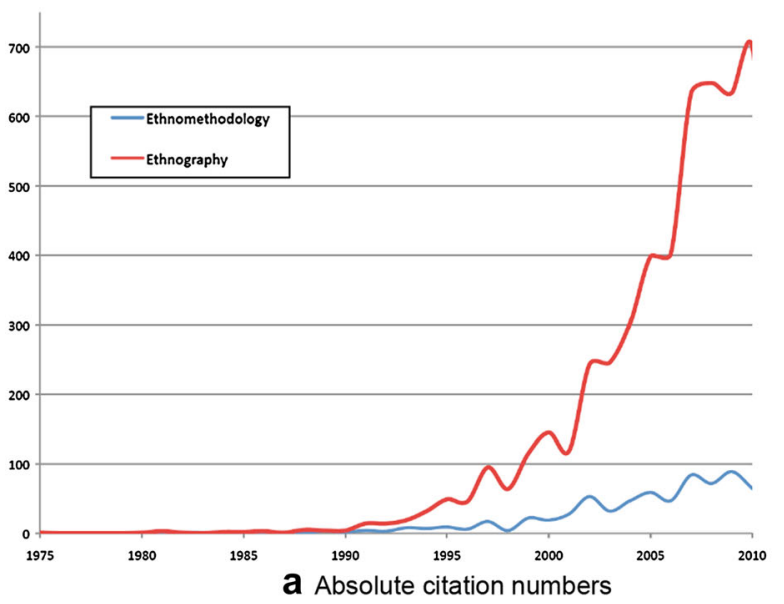

Fig. 1 Comparison of entries in the ACM digital library for papers containing the word ethnography (ic/ically) as opposed to the word ethnomethodology (ical/ically). We show a absolute numbers of

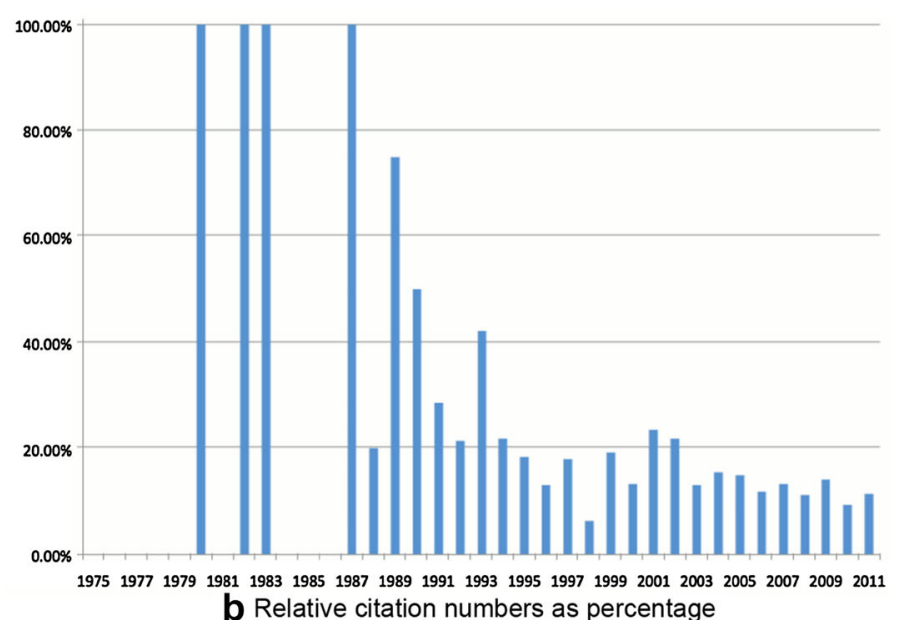

papers containing each word and $\mathbf{b}$ relative proportion of those publications referring to ethnography that explicitly mention ethnomethodology (all searches conducted on 12/9/2011) 
theoretical or explanatory one. The approach has resulted in rich descriptions of work in context, proving valuable to ubicomp, but also in difficulties when meshing its practices with alternative accounts. In particular, by creating a dichotomy between ethnomethodology and all other sociology, other theoretical perspectives and methodological procedures are grouped together under the heading of "all sociology which is not ethnomethodology". This rhetorical strategy allows the authors to claim that ethnomethodology has a unique concern for the world as it is.

In addition to the influence of ethnomethodology on the EuroPARC HCI researchers-the "bastard children" that Garfinkel was pleased to claim-we should also consider the reciprocal influence that EuroPARC has had on ethnomethodology. In the photobook "Garfinkel's Study" [18], circulated by Garfinkel and widely interpreted as Garfinkel's definitive list of who was in and who was out of favour in his definition of ethnomethodology, 8 of the 32 papers cited in the bibliography as "a curriculum of ethnomethodology" are by employees of Xerox (Orr and Suchman at PARC, Anderson, Button, Luff and Dourish at EuroPARC). There have been very few previous cases where a single company left such a significant legacy within a defined social science discipline.

\subsection{Implications for design}

A technology corporation such as Xerox understands the role of its research laboratories as inventing new technologies that will eventually become profitable productssubject to the standard corporate processes of market research, design and manufacturing. Government policy in the UK and USA increasingly proposes an economic role of this kind for universities or for the academy as a whole. However, Bob Anderson, the first ethnomethodologist to direct EuroPARC, reflected in our interview that the contribution of ethnomethodology should perhaps be understood as one of market research, rather than design.

Some prominent designers, including Apple's Jonathan Ive, publicly discount any independent role for user research in design, whether based on social science, controlled laboratory studies, or cognitive modelling. Ive observes in his public addresses that user needs are central to the work of any designer, that the consideration of users is always completely integrated with the other mechanical and conceptual elements of design practice, and that usercentred design cannot be segregated into a research laboratory context. However, to the extent that $\mathrm{HCI}$ is a scientific field, interaction design researchers are obliged to ask whether user-centred design is best realised through technical innovation that is informed by empathy for users, through rigorous social scientific research that can be defended within a technical frame of reference, or through a pragmatic bricolage that is adopted in response to the concerns of a specific design objective [46].

Whether or not design can properly be accommodated within a scientific context [5], our study raises the question of how one should "design" an HCI laboratory that will be relevant to a corporate setting (or indeed a governmentfunded research commercialisation programme). Despite its origins within a corporate research laboratory in the grand twentieth-century tradition, John Seely Brown's agenda of radical interdisciplinarity did create a different kind of institution at EuroPARC. Rather than a High Church cathedral of basic research, we were told that the scientific environment at EuroPARC was "a train-wreck, it was carnivale". The transition from the high modernism of cybernetic technocracy at PARC, to the interdisciplinary "carnivale" of EuroPARC, casts Garfinkel in the mischievous role of the "lord of misrule" who would subvert social order in a mediaeval carnival. As described by Bakhtin, those ancient subversive traditions might be a valuable counter to the ordered social structures of modernism [4], but his use of Stalin as an exemplar also shows that ideological overturn of the social order need not be liberating [47].

The changing intellectual generations of HCI have been led by a variety of theoretical champions, but the real achievement is arguably that of the interdisciplinary collaborators who adopt research methods and analytic stances on pragmatic grounds and who bring an ethical commitment to negotiation of the corporate environment and empathetic defence of users against potentially exploitative commercial goals. If corporations (or governments) continue to commission research activities as advanced product design, then this research will necessarily be conducted, like all design, by interdisciplinary teams. Purity of research methodology or of theoretical agendas may appeal to a High Church of research evaluators, but the practical entanglement of ubicomp with everyday life will continue to resemble a Low Church of evangelical fervour. We envisage that international research culture will quite likely continue to be dominated by High Church conflations of theory and influence, in the same manner observed throughout the human history of kingdoms and priesthoods.

The social dynamics of the debates around ethnomethodology, as discussed in this paper, were bound up in the idealist legacy of the 1960s. European critical theory and Californian libertarianism constructed bodies of discourse and research practice that, while concerned with analysis of the everyday, were already unfashionable among young graduates in Thatcher's Britain at the time EuroPARC was established. Was the colonisation of HCI by ethnomethodology simply a problem for an older generation, which can be forgotten now that young design 
researchers have developed their own bricolage of ubicomp research methods?

Our view is that while specific meeting points of theories and research methods may change, global capitalist concern with market profits sustains an unlikely democracy, calling attention to the everyday lives of consumers, even as it simultaneously exploits them. As a result, corporate research must continue to sustain a balance between High and Low Churches, just as ethnomethodology did at EuroPARC. Explicit comparison to draw lessons from church history may continue to be beneficial, especially within the postmodern context of new religious movements and contemporary spirituality of social justice, environmentalism and personal well-being.

Acknowledgements We would like to thank our interviewees and informants: Abigail Sellen, Allan MacLean, Andy Hopper, Austin Henderson, Bill Buxton, Bill Gaver, Bob Anderson, Danny Bobrow, David Good, Elizabeth Churchill, Gitte Jordan, Graham Button, Liam Bannon, Lucy Suchman, Michael Lynch, Paul Dourish, Phil Barnard, Quentin Stafford-Fraser, Rachel Hewson, Richard Harper, Richard Young, Satinder Gill, Simon Buckingham-Shum, Steve Woolgar, Thomas Green, Victoria Bellotti and William Newman. We are grateful to both named and anonymous reviewers of earlier versions of this manuscript. Except where specifically noted in the text, opinions expressed in this paper are our own interpretations and should not be attributed to all or any of these individuals. This paper is dedicated to the memory of Gitte Jordan.

Open Access This article is distributed under the terms of the Creative Commons Attribution 4.0 International License (http://crea tivecommons.org/licenses/by/4.0/), which permits unrestricted use, distribution, and reproduction in any medium, provided you give appropriate credit to the original author(s) and the source, provide a link to the Creative Commons license, and indicate if changes were made.

\section{References}

1. Anderson RJ, Butler OR (2009) Industrial R\&D in transition. Phys Today 62(7):36-41

2. Anon (2005). Notes on the work of the Medical Research Council Applied Psychology Unit 1944-1997. http://www.mrc-cbu.cam. ac.uk/history/legacyconference/briefingnotes.html)

3. Baird D (1999) Internal history and the philosophy of experiment. Perspect Sci 7(3):383-407

4. Bakhtin MM (1965) Rabelais and his world. Trans. Hélène Iswolsky. Indiana University Press, Bloomington

5. Blackwell AF (2008) Design research and academic disciplines. Des Res Quart 3(4):3-8

6. Blythe MA, Wright PC (2006) Pastiche scenarios: Fiction as a resource for user centred design. Interact Comput 18(5):1139-1164

7. Burton S (1973) Carlos Castaneda: Magic and Reality (cover article). Time Magazine

8. Butler P (1998) From Early Eighteenth Century to the Present Day. In SW Sykes, JE Booty,J Knight (eds) The study of Anglicanism, Rev. London: SPCK

9. Buxton W, Moran T (1990) EuroPARC's Integrated Interactive Intermedia Facility (iiif): Early Experience, In Gibbs S Verrijn-
Stuart SS (eds). Multiuser interfaces and applicationsIn: Proceedings of the IFIP WG 8.4 conference on multi-user interfaces and applications, Heraklion, Crete. Amsterdam: Elsevier Science Publishers B.V. (North-Holland), pp 11-34

10. Card S, Moran T, Newell A (1983) The psychology of humancomputer interaction. Lawrence Erlbaum Associates, Hillsdale, NJ

11. Crabtree A (2003) designing collaborative systems: a practical guide to ethnography. Springer

12. Crabtree A, Rodden T, Tolmie P, Button G (2009) Ethnography considered harmful. Proc CHI' 2009:879-888

13. Debord G (1967, tr. 1987) Society of the Spectacle. (K. Knabb, Trans.). London: Rebel Press

14. Denzin N, Lincoln Y (2005) The sage handbook of qualitative research, 3rd edn. Sage Publications, Thousand Oaks

15. Dourish P (2001) Where the action is: the foundations of embodied interaction. MIT Press

16. Gardiner ME (2000) Critiques of everyday life. Routledge

17. Garfinkel H (1967) Studies in ethnomethodology. University of California, Los Angeles

18. Garfinkel H (2009) Garfinkel's study. Self-published photobook

19. Gellner E (1975) Ethnomethodology: the re-enchantment industry or The Californian way of subjectivity. Phil Soc Sci 5:431-450

20. Gill S (1995) Dialogue and tacit knowledge for knowledge transfer. Unpublished Ph.D. thesis, University of Cambridge

21. Glaser BG, Strauss AL (1967) Discovery of grounded theory: strategies for qualitative research

22. Harper R (2009) From tele-presence to human absence: the pragmatic construction of the human in communications systems research. Proceedings of the 23rd British HCI Group Annual Conference on People and Computers: Celebrating People and Technology (BCS-HCI '09). British Computer Society, Swinton, pp 73-82

23. Harris M (1979) Cultural materialism: The struggle for a science of culture. Random House, New York

24. Jenkins G (1977) Empire building: the remarkable real-life story of star wars. Citadel Press

25. Kincheloe JL (2001) Describing the bricolage: conceptualizing a new rigor in qualitative research. Qualit Inq 7(6):679-692

26. Kirk K, Cotton C (2012) The Cambridge phenomenon: 50 years of innovation and enterprise. Third Millennium Information, London

27. Lederberg J (1963) An Instrumentation Crisis in Biology. National Library of Medicine correspondence archive, proposal reference BBGCVS. http://profiles.nlm.nih.gov/ps/access/ BBGCVS.pdf

28. Lefebvre H (1971) Everyday life in the modern world, tr. S. Rabinovitch. Transaction Books, New Brunswick

29. Lynch M (1997) Scientific practice and ordinary action: ethnomethodology and social studies of science. Cambridge University Press

30. Mandell AJ (1977). Is Don Juan Alive and Well? from The Ontario Review, republished in B. Henderson (Ed) The Pushcart Prize: Best of the Small Presses (Vol. II). Pushcart Press, pp 199-208

31. Meehan P (2009) Cinema of the psychic realm: a critical survey. McFarland \& Co

32. Morgan D, Stanley L (1992) Debates in sociology. Manchester University Press, Manchester

33. Newell A (1974) Notes on a proposal for a psychological research unit. Xerox Palo Alto Research Center Applied Informationprocessing Psychology Project, AIP Memo, p 1

34. Newman W, Sproull R (1973) Principles of interactive computer graphics, first edition 
35. Nowotny, H. (2008). Insatiable curiosity: innovation in a fragile future. (M. Cohen, Trans.) MIT Press

36. Robson C (2011) Real world research (3rd Ed). John Wiley \& Sons

37. Segal Quince et al (1985) The Cambridge Phenomenon: The growth of high technology industry in a university town

38. Simon HA (1969) The sciences of the artificial. MIT Press, Cambridge, MA

39. Smith DK, Alexander RC (1988) Fumbling the future: how Xerox invented, then ignored, the first personal computer. Morrow

40. Suchman L (1987) Plans and situated actions: the problem of human-machine communication. Cambridge University Press, New York

41. Suchman L (2006) Human-machine reconfigurations: plans and situated actions. Cambridge University Press, Cambridge
42. Thrift N (2006) Re-inventing invention: new tendencies in capitalist commodification. Econ Soc 35(2):279-306

43. Want R, Hopper A, Falcão V, Gibbons J (1992) The active badge location system. ACM Trans Inf Syst 10(1):91-102. doi:10.1145/ 128756.128759

44. Weiser M (1991) The computer for the 21st century. Sci Am 265(3):78-89

45. Wellner P (1993) Interacting with paper on the DigitalDesk. Commun ACM 36(7):87-96

46. Yee JSR, Bremner C (2011) Methodological Bricolage-What does it tell us about Design? Doctoral Education in Design Conference. Hong Kong, Hong Kong Polytechnic University. http:// www.sd.polyu.edu.hk/DocEduDesign2011/doc/papers/313.pdf

47. Zizek S (2005) The two totalitarianisms. Lond Rev Books 27(6): 17 